Gut, 1984, 25, 508-512

\title{
Value of serum PABA as a pancreatic function test
}

\author{
C LANG, K GYR, I TONKO, D CONEN, AND G A STALDER \\ From the Division of Gastroenterology and Medical Outpatient Department, University (Kantons) Hospital, \\ Basel, Switzerland
}

SUMMARY In a total of 71 subjects (19 controls, 24 patients with non-pancreatic gastrointestinal disease, and 27 patients with pancreatic disease) an oral pancreatic function test using N-benzoyl-L-tyrosyl-PABA (BT-PABA) was performed with simultaneous determination of the serum para-aminobenzoic acid (PABA). Urinary excretion of PABA was significantly less $(p<0.001)$ in patients with chronic pancreatitis $(n=12)$ and pancreatic carcinoma $(n=10)$ than in controls and in patients with non-pancreatic disease. The serum concentration curve in patients with chronic pancreatitis was significantly flattened $(p<0 \cdot 001)$ compared with that of the control group and the patients with non-pancreatic gastrointestinal disease. The discrimination between the controls and the patients with chronic pancreatitis was best at 120 minutes after administration of BT-PABA (lower limit of normal: $2 \cdot 8 \mu \mathrm{g} / \mathrm{ml}$ ). The results of our study show that determination of PABA serum concentration two hours after administration of BT-PABA is as valuable an index of pancreatic function as the urinary excretion of PABA.

The oral pancreatic function test using N-benzoyl-Ltyrosyl-para-aminobenzoic acid (BT-PABA) has proved to be a simple and reliable test in detecting moderate to severe exocrine pancreatic insufficiency. In over 900 patients and controls tested we found a sensitivity of $85 \%$ for chronic pancreatitis and a specificity of $90 \%$, which correlates well with the data from other European studies. ${ }^{1-5}$ In our experience, however, the value of the test depends to a large extent on a correctly conducted urinary collection. In some patients, particularly in elderly, severe debilitated patients, those with urological disorders, and in children, an inaccurate collection of urine will invalidate the results of the test.

It has recently become possible to measure the PABA in the serum after administration of BTPABA. The serum concentration profile of PABA in patients with exocrine pancreatic insufficiency was shown to be significantly lower than that found in healthy controls. ${ }^{6-8}$ The data are, however, too few to allow any conclusion on the value of the procedure; and furthermore, methodology of pancreatic function test used in the studies varied from one group of investigators to another. Determination of PABA in the serum instead of urine could represent an alternative pancreatic

Address for correspondence: PD Dr K Gyr. Division of Gastroenterology. Kantonsspital. $\mathrm{CH}-4$ (1)31 Basel. Switzerland.

Received for publication 19 August 1983 function test procedure in patients in whom urinary collection is expected to be unreliable. It was the aim of this study to examine the value of the serum determination of PABA in comparison with the urinary PABA excretion in healthy controls, in patients with extra-abdominal pathology, and with non-pancreatic, gastrointestinal diseases as well as in patients with pancreatic diseases, especially exocrine pancreatic insufficiency.

\section{Methods}

\section{PATIENTS}

Oral pancreatic function tests with determination of PABA in the urine and serum were carried out in a total of 71 patients and controls between 1981 and 1982.

\section{CONTROLS}

The control group consisted of 10 healthy volunteers (seven men and three women), aged 24 to 29 years, and nine patients of the outpatient department (six men and nine women), aged 19 to 65 years, with extra-abdominal disease, but without organic disease of the gastrointestinal tract. Patients with evidence of renal disease were excluded.

PATIENTS WITH NON-PANCREATIC

GASTROINTESTINAL DISEASE

Twenty four patients (12 men and 12 women), aged 
22 to 79 years, with various gastrointestinal complaints were examined. Five patients had liver and biliary tract disease, eight having had gastric resection, 11 gastrointestinal diseases including inflammatory bowel disease (two), adult coeliac disease (two), diarrhoea (one), gastric polyposis (one), functional gastrointestinal disorders (five). All of these patients underwent thorough clinical and laboratory investigations to exclude pancreatic disease. If found necessary, sonotomography $(n=10)$, ERCP $(n=5)$, computerised tomography $(n=2)$, and Lundh test $(n=3)$ were performed in addition.

PATIENTS WITH PANCREATIC DISEASES

Twenty seven patients (17 men and 10 women), aged 32 to 87 years, with disease of the pancreas were included in the study. Five patients had acute relapsing pancreatitis, 12 chronic pancreatitis, and 10 pancreatic carcinoma. The diagnosis of acute pancreatitis was based on the patient's history, clinical signs, and raised serum amylase and/or lipase. The criteria of the diagnosis of chronic pancreatitis were as used before.

The diagnosis of carcinoma of the pancreas was verified either by surgery or at necropsy in all patients.

Renal function was assessed by the serum creatinine level which was measured in all patients except the healthy volunteers, one out of the nine patients with extra-abdominal diseases, and three out of the 24 patients with non-pancreatic gastrointestinal diseases. All values were within normal limits.

ORAL PANCREATIC FUNCTION TEST

BT-PABA (PFT Roche) was given in the form of three tablets each containing $333 \mathrm{mg}$ of the peptide together with a breakfast consisting of one roll, $10 \mathrm{~g}$ of butter, jam, and $200 \mathrm{ml}$ of tea. During the first hour, the patients were encouraged to drink an additional $400 \mathrm{ml}$ of water or tea to ensure sufficient diuresis, and after four to five hours a lunch was allowed. The urine was collected in a single specimen over six hours, during which time blood samples of $10 \mathrm{ml}$ were taken every hour. The blood was centrifuged and the serum frozen at $-20^{\circ} \mathrm{C}$. Before administration of BT-PABA, control urine was collected for one hour and a fasting blood sample was also taken (control value).

DETERMINATION OF PABA IN URINE AND SERUM The PABA in the urine was determined according to the Bratton-Marshall method following hydrolysis with $30 \%$ hydrochloric acid for one hour at $100^{\circ} \mathrm{C} .{ }^{10}$ The results were expressed as the amount of PABA excreted in the urine during six hours as percentage of the administered dose - that is, of $340 \mathrm{mg}$ PABA. According to previous studies, $50 \%$ urinary PABA excretion within six hours was taken as lower limit of normal. ${ }^{9}$

The determination of PABA in the serum was preceded by deproteinisation of the serum samples: $1 \mathrm{ml}$ serum was mixed with $2 \mathrm{ml} 10 \%$ trichloroacetic acid and centrifuged at $40000 \mathrm{rpm}$ for 10 minutes. The supernatant was collected in a $5 \mathrm{ml}$ Erlenmaier dish. The sediment was resuspended in $1 \mathrm{ml} 10 \%$ trichloroacetic acid and subsequently centrifuged. This procedure was performed twice. The supernatant was then added to the contents of the Erlenmaier dish. Finally, $10 \%$ trichloroacetic acid was added to the supernatant up to a total of $5 \mathrm{ml}$. After deproteinisation, $2 \mathrm{ml}$ of the supernatant were incubated with $0.2 \mathrm{ml} 30 \%$ hydrochloric acid for one hour at $100^{\circ} \mathrm{C}$. Subsequent to the hydrolysis the concentration of para-aminobenzoic acid was determined photometrically by the BrattonMarshall method at $546 \mathrm{~nm}$ wavelength. The measurement of the extinction was taken against the control serum sample treated the same way and multiplied with a correction factor $(2 \cdot 6666)$ to obtain the extinction per millilitre of serum. By means of a standard calibration curve, the concentration of para-aminobenzoic acid in the serum was expressed in $\mu \mathrm{g} / \mathrm{ml}$. Intra-assay variation was $1.6 \%(\mathrm{n}=6)$ and interassay variation $7 \cdot 4 \%(n=4)$.

\section{STATISTICAL ANALYSIS}

Results are expressed as mean \pm standard deviation. Student's $t$ test for paired and unpaired data was used to test for differences of the means. Regression analysis was performed according to Remington and Shork. ${ }^{11}$

\section{Results}

SIX HOUR URINARY EXCRETION OF PABA

The patients with chronic pancreatitis and carcinoma of the pancreas excreted significantly less PABA than the controls $(\mathrm{p}<0.001)$ as shown in Table 1. There was no significant difference between the urinary excretion of PABA in patients with acute pancreatitis or non-pancreatic gastrointestinal disease and that in the controls.

SERUM CONCENTRATION OF PABA

Controls

The mean serum PABA concentrations over a period of up to 360 minutes in the 19 controls are shown in Table 2 . A peak concentration of $4 \cdot 8 \pm 1 \cdot 1$ $\mu \mathrm{g} / \mathrm{ml}$ was reached at 180 minutes. In comparison with the patients with chronic pancreatitis and 
Table 1 Six hour urinary excretion of PABA in percentage of administered dose in controls $(n=19)$, non-pancreatic gastrointestinal diseases $(n=24)$, acute pancreatitis $(n=5)$, chronic pancreatitis $(n=12)$, and pancreatic carcinoma $(n=10)$

\begin{tabular}{lllll}
\hline Controls & $\begin{array}{l}\text { Non-pancreatic } \\
\text { gastrointestinal diseases }\end{array}$ & Acute pancreatitis & Chronic pancreatitis & Pancreatic carcinoma \\
\hline $73 \cdot 0 \pm 13 \cdot 7$ & $68 \cdot 8 \pm 2(0 \cdot 4$ & $6(0) \cdot 8 \pm 22 \cdot 2$ & $27 \cdot 7 \pm 14 \cdot 1$ & $39 \cdot 6 \pm 18 \cdot 2$ \\
& NS & NS & $\mathrm{p}<0 \cdot(0) 1$ & $\mathrm{p}<0 \cdot 001$ \\
\hline
\end{tabular}

Level of significance is always given in comparison with the controls.

NS $=$ not significant.

pancreatic carcinoma, discrimination was best at 120 minutes after administration of the peptide (Fig. 1). Assuming a log normal distribution for the control data at 120 minutes, the lower limit of normal was calculated as mean ${ }_{\log 10}-2 \mathrm{SD}_{\log 10}$ resulting in 2.75 $\mu \mathrm{g} / \mathrm{ml}$, which was fixed at $2 \cdot 8 \mu \mathrm{g} / \mathrm{ml}$ for practical reasons. The individual PABA serum concentrations at 120 minutes and the urinary six hour excretion of PABA are shown in Fig. 2.

One control patient with exercise induced asthma had a serum PABA concentration of $2.5 \mu \mathrm{g} / \mathrm{ml}$, just below the lower limit of normal (Fig. 2). The PABA excretion in the urine in this patient, however, was normal $(75 \cdot 3 \%)$. Another control patient had an abnormally low urinary excretion $(31.7 \%)$ but his serum PABA concentration was normal $(6 \cdot 1 \mu \mathrm{g} /$ $\mathrm{ml})$. In this latter patient, an incorrect urinary collection was suspected because of language difficulty. Both patients had no signs or symptoms of pancreatic disease.

Patients with non-pancreatic gastrointestinal disease The serum concentration curve of PABA followed the pattern of that of the controls closely, there being no significant difference between the two (Fig. 1). In this group of 24 patients, one patient with irritable colon had an abnormal serum value of $2 \cdot 1 \mu \mathrm{g} / \mathrm{ml}$ but had a normal urinary PABA excretion $(60.6 \%)$ (Fig. 2). Four patients with normal PABA serum concentration showed urinary PABA excretion below the normal range. One of these patients suffered from an anastomotic ulcer after Billroth II gastric resection and also had prostatic hypertrophy with retention of urine, the other three had posthepatic cirrhosis, Billroth I gastric resection, and total gastric resection respectively.

Patients with pancreatic disease

In the five patients who had an acute pancreatitis, their mean serum PABA values were slighly lower than those of the controls, but the differences were not statistically significant (Table 2 ).

In contrast with patients with acute pancreatitis and with controls, the serum concentration curve of the patients with chronic pancreatitis was considerably flattened with a delayed, low peak concentration $(2 \cdot 4 \pm 0.9 \mu \mathrm{g} / \mathrm{ml})$ occurring at 300 minutes. The PABA concentrations at $60,120,180$, and 240 minutes were significantly lower than the corresponding values of the control group $(p<0 \cdot 01-$ 0.001 ; Fig. 1). In all 12 patients with chronic pancreatitis, the serum PABA concentration was abnormally low at 120 minutes (Fig. 2).

In the 10 patients with pancreatic carcinoma, the rate of increase in serum PABA concentrations was also significantly lower than that of the controls, and a peak concentration $(4 \cdot 8 \pm 2 \cdot 3 \mu \mathrm{g} / \mathrm{ml})$ was reached at 300 minutes (Fig. 1). In two of the patients with pancreatic carcinoma, the serum PABA values at 120 minutes and urinary PABA excretion were normal.

\section{Discussion}

The oral pancreatic function test with measurement of urinary PABA excretion has proved to be a simple and reliable diagnostic test in pancreatic disease, especially in chronic pancreatitis. ${ }^{-5}{ }^{9}$ In our experience, however, as well as those of others, the test is of no value if the urinary collection is

Table 2 PABA serum concentrations of controls $(n=19)$ and patients with acute pancreatitis $(n=5)$ in $\mu \mathrm{g} / \mathrm{ml}$

\begin{tabular}{|c|c|c|c|c|c|c|}
\hline $\begin{array}{l}\text { Time after administration } \\
\text { of } B T-P A B A\end{array}$ & $60 \mathrm{~min}$ & $120 \mathrm{~min}$ & $180 \mathrm{~min}$ & $240 \mathrm{~min}$ & $300 \mathrm{~min}$ & $360 \mathrm{~min}$ \\
\hline Controls & $\begin{array}{l}2 \cdot 5 \pm 1 \cdot 7 \\
\text { NS }\end{array}$ & $\begin{array}{l}4 \cdot 7 \pm 1 \cdot 2 \\
\text { NS }\end{array}$ & $\begin{array}{l}4 \cdot 8 \pm 1 \cdot 1 \\
\text { NS }\end{array}$ & $\begin{array}{l}4 \cdot 3 \pm 1 \cdot 3 \\
\mathrm{NS}\end{array}$ & $\begin{array}{l}3 \cdot 4 \pm 1 \cdot 5 \\
\text { NS }\end{array}$ & $\begin{array}{l}2 \cdot 4 \pm 1 \cdot 3 \\
\text { NS }\end{array}$ \\
\hline Acute pancreatitis & $1 \cdot 4 \pm 1 \cdot 0$ & $3 \cdot 3 \pm 2 \cdot 1$ & $4 \cdot 4 \pm 2 \cdot 4$ & $4 \cdot 3 \pm 1 \cdot 4$ & $3 \cdot 4 \pm 0 \cdot 7$ & $3 \cdot 1 \pm 1 \cdot 0$ \\
\hline
\end{tabular}


Fig. 1 PABA serum concentration at various specific times after administration of $B T-P A B A$ in controls $(n=19)$, patients with non-pancreatic gastrointestinal diseases $(n=24)$, chronic pancreatitis $(n=12)$, and pancreatic carcinoma $(n=10)$.

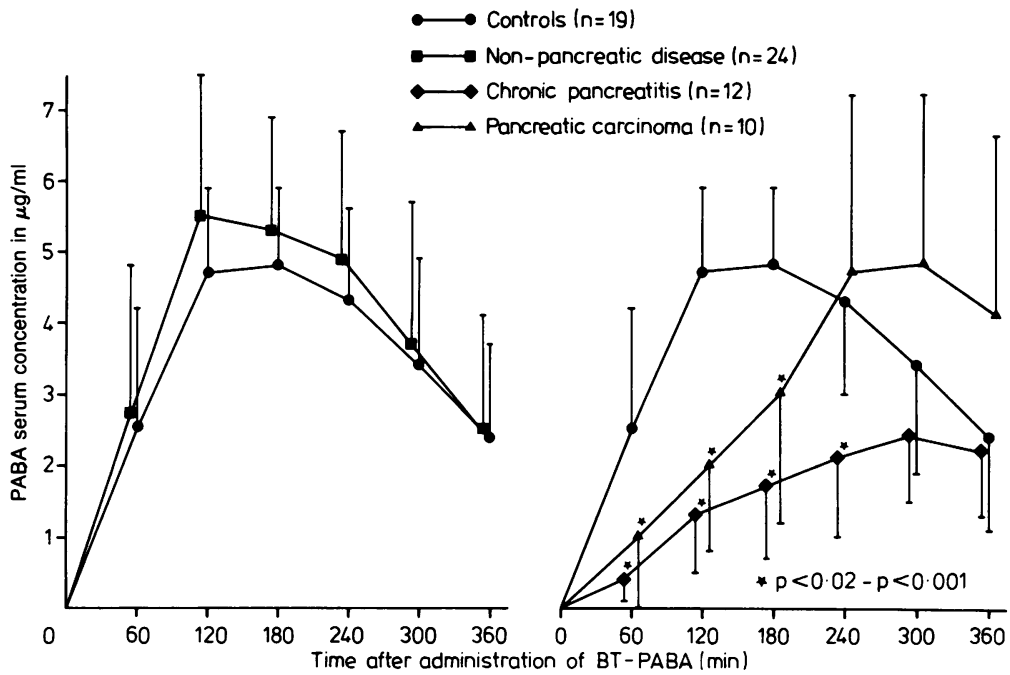

pancreatic gastrointestinal diseases. Similarly, the serum PABA profile was flattened in chronic pancreatitis. In patients with pancreatic carcinoma, the slope of the curve was also significantly lower, the same peak concentration was reached as in the control group, but was delayed until 300 minutes.
Fig. $2 P A B A$ serum concentration 120 minutes after administration of $B T-P A B A$ in comparison with six hour $P A B A$ excretions in controls $(n=19)$, patients with nonpancreatic gastrointestinal diseases $(n=24)$, chronic pancreatitis $(n=12)$, and pancreatic carcinoma $(n=10)$.

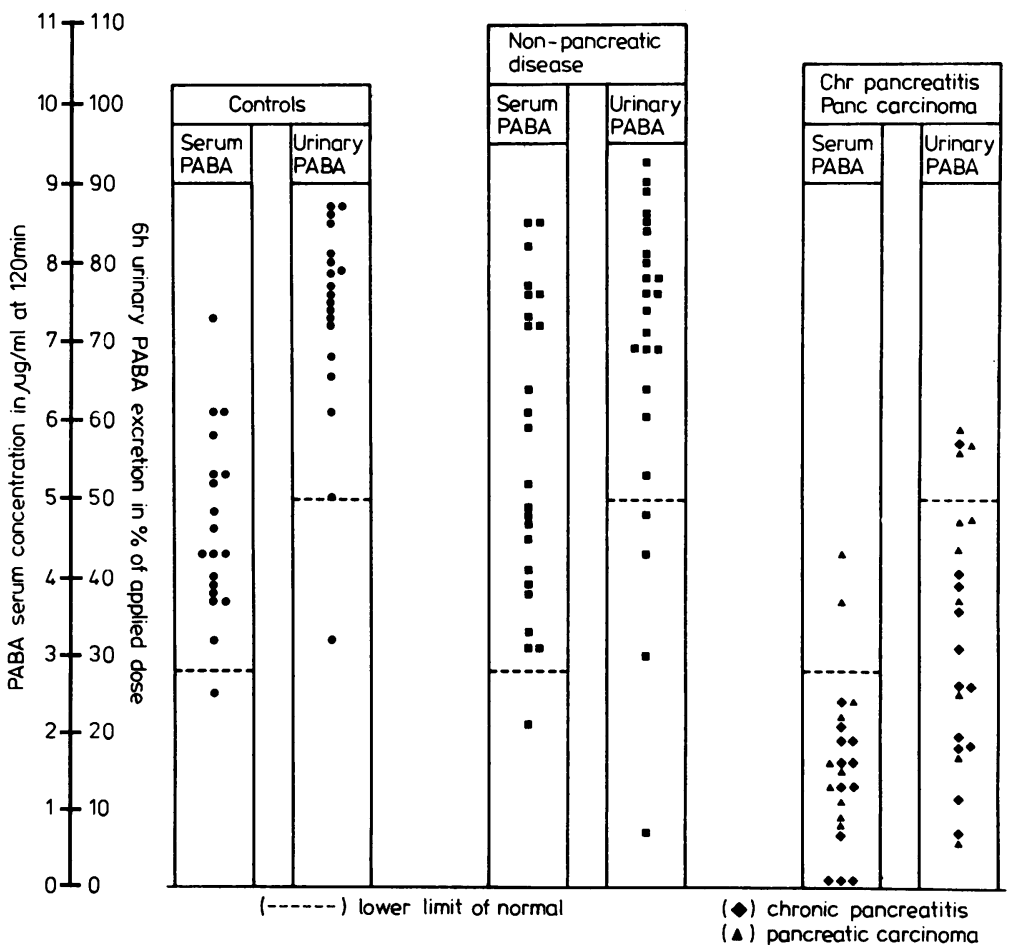


All 12 patients with chronic pancreatitis had an abnormally low serum PABA concentration, while 11 out of $12(92 \%)$ had an abnormal urinary PABA excretion. In eight out of the 10 patients with pancreatic carcinoma, the serum PABA concentration was below normal $(80 \%)$, and in seven of these 10 patients $(70 \%)$ the urinary excretion was also abnormal. These results are close to the sensitivity previously reported for the standard pancreatic function test. ${ }^{9}$ On the other hand, 18 of 19 controls (95\%) and 23 of 24 patients with non-pancreatic disease $(96 \%)$ had normal serum PABA concentrations, while urinary PABA excretion was normal in 18 of 19 controls $(95 \%)$ and 21 of 24 patients $(87 \%)$ respectively.

The results thus show that determination of PABA serum concentration at two hours after administration of BT-PABA is as valuable an index of exocrine pancreatic function as the urinary PABA excretion. Furthermore, this will exclude those false positive (abnormally low) results caused by faulty urine collection.

The determination of PABA in the serum can therefore be recommended in all those patients in whom urinary collection is impossible or its reliability dubious. It has been proved recently to be valuable in children also. ${ }^{12}$ Fasting blood samples and a two hour blood sample after BT-PABA administration appear to be sufficient. It must, however, be realised that the pancreatic function test with determination of the serum PABA is a more invasive procedure than the classical urinary pancreatic function test and the measurement of serum PABA more fastidious than that of urinary PABA.

The question as to whether the serum PABA is superior in accuracy to that of the urinary excretion cannot be resolved by the results of the limited number of patients investigated. There appears to be a trend in favour of the former, however, especially with regard to specificity as reported by others. ${ }^{6-8}$

According to our results, a combination of both the PABA serum concentration and PABA urinary excretion will increase the diagnostic value of the pancreatic function test. If the combined pancreatic function test can be taken as normal when only one of the criteria is within the normal limits, then all of our controls and patients with non-pancreatic gastrointestinal disease had a normal pancreatic function test, while 11 of 12 patients with chronic pancreatitis and seven of 10 with pancreatic carcinoma had an abnormal test. The combination therefore increases the specificity without decreasing the sensitivity of the pancreatic function test below that of the urinary PABA excretion alone. Further prospective investigation will help verify the validity of this conclusion.

We sincerely thank Mrs Carita Frei for typing the manuscript and setting up the graphs.

\section{References}

1 Bornschein W, Goldmann FL, Dressler J. Diagnostik der exokrinen Pankreasinsuffizienz mit einem synthetischen chymotrypsinspezifischen Peptid. Klin Wochenschr 1978; 56: 197-205.

2 Freise J, Hofmann R. Zur Spezifität des Peptid-PABATests. Z Gastroenterol 1979; 17: 310-7.

3 Lankisch PG, Ehrhardt-Schmelzer S, Koop H, Caspary WF. Der NBT-PABA-Test in der Diagnostik der exokrinen Pankreasinsuffizienz. Dtsch Med Wochenschr 1980; 105: 1418-23.

4 Thienhaus R, Niederau C. Die Untersuchung der exokrinen Pankreasfunktion mit N-Benzoyl-L-Tyrosylp-Aminobenzoesäure. Z Gastroenterol 1979; 17: 18794.

5 Ribet A, Frexinos J, Escourrou J, Vaysse N, Arany Y, Varignon $M$. Etude indirecte de la sécrétion exocrine du pancréas par administration orale d'un peptide synthétique (PABA test). Gastroenterol Clin Biol 1979; 3: 227-34.

6 Bornschein W. Der PABA-Peptid-Serum-Test. Dtsch Med Wochenschr 1981; 106: 1676-7.

7 Wolf C, Ehrig C, Brunner H. Paraaminobenzoesäurespiegel im Serum nach Gabe von N-Benzoyl-L-tyrosylParaaminobenzoesäure als Suchtest der exkretorischen Pankreasfunktion. Schweiz Med Wochenschr 1981; 111: 343-7.

8 Delchier JC, Soule JC. BT-PABA test with plasma PABA measurements: evaluation of sensitivity and specificity. Gut 1983; 24: 318-25.

9 Lang C, Gyr K, Stalder GA. Gillessen D. Assessment of exocrine pancreatic function by oral administration of N-benzoyl-L-tyrosyl-p-aminobenzoic acid (Bentiromide); 5 years' clinical experience. Br J Surg 1981; 68: 771-5.

10 Bratton AC, Marshall EK Jr. A new coupling component for sulfanilamide determination. J Biol Chem 1939; 128: 537-50.

11 Remington RD, Shork MA. Statistics with applications to the biological and health sciences. Englewood Cliffs, NJ: Prentice Hall, 1970.

12 Dockter G, Nacu I, Kohlberger E. Determination of protease-cleaved p-aminobenzoic acid (PABA) in serum after oral administration of N-benzoyl-L-tyrosylp-aminobenzoic acid (PABA-peptide) in children. Eur J Pediatr 1981; 135: 277-9. 